\title{
ANALISIS PERENCANAAN PARTISIPATIF TERHADAP PENCAPAIAN KINERJA PEGAWAI PADA KANTOR SEKRETARIAT DPRD KOTA GUNUNGSITOLI
}

\author{
Eduar Baene \\ STIE Pembangunan Nasional \\ J1. Karet No.30, Ps. Gn. Sitoli, Gn. Sitoli, Kota Gunungsitoli, Sumatera Utara \\ eduar.baene@gmail.com
}

\begin{abstract}
Planning is the process of defining organizational goals, making strategies to achieve that goal, and developing plans for organizational work activities. While performance is what is done and what is not done by employees is the work that has been achieved by employees. The purpose of this study was to determine the effect of participatory planning on employee performance at the Secretariat of the Regional Representatives Office of the Gunungsitoli City. In this study the authors analyzed the research data using quantitative methods. The dependent variable $(\mathrm{Y})$ of this study is performance, while the independent variable (X) is planning. The population in this study were all employees in the Secretariat Office of Gunungsitoli City DPRD, while the sample was 24 people. Based on the data collected from the research conducted, the results were obtained that there was an influence of participatory planning on employee performance at the Gunungsitoli City DPRD Secretariat Office ".
\end{abstract}

\section{Keyword: Participatory Planning, Performance}

\section{PENDAHULUAN}

Seiring dengan perkembangan zaman dan kemajuan teknologi yang semakin pesat maka dengan sendirinya kebutuhan manusia semakin besar juga, salah satunya adalah pelayanan yang lebih baik.Dalam pemenuhan kebutuhan ini tentu tidak semudah membalikkan telapak tangan. Kalau kita melihat fenomena yang terjadi di tengahtengah masyarakat, ada desakan perubahan atas krisis kepercayaan masyarakat terhadap birokrasi, itu menunjukkan bahwa rendahnya kualitas pelayanan organisasi pemerintah dalam memenuhi kewajibannya kepada masyarakat.

Dalam pembangunan sekarang ini peningkatan suatu organisasi mutlak diperlukan perencanaan. Hal ini merupakan salah satu proses atau merubah suatu keadaan untuk mencapai maksud yang dituju oleh perencana atau oleh orang/badan yang diwakili oleh perencanaan itu. Perencanaan itu meliputi: Analisis, kebijakan dan rancangan. Pada intinya perencanaan dibuat sebagai upaya untuk merumuskan apa yang 
sesungguhnya ingin dicapai oleh sebuah organisasi atau instansi serta bagaimana sesuatu yang ingin dicapai tersebut dapat diwujudkan melalui serangkaian rumusan rencana kegiatan tertentu.

Dewan Perwakilan Rakyat Daerah, selanjutnya disingkat DPRD, merupakan salah satu lembaga yang sangat berpengaruh peranannya dalam pembangunan. Sebagai bukti peranan lembaga yang dimaksudkan, secara jelas telah ditegaskan dalam Undang-Undang Nomor 32 Tahun 2004 tentang Pemerintahan Daerah bahwa DPRD merupakan Lembaga Perwakilan Rakyat Daerah dan berkedudukan sebagai unsur penyelenggara pemerintahan Daerah. Dalam melaksanakan fungsi-fungsi Pemerintahan Daerah, DPRD memiliki 3 (tiga) fungsi antara lain: (1) fungsi legislasi, yaitu fungsi DPRD untuk membentuk Peraturan Daerah bersama-sama Pemerintah Daerah; (2) Fungsi Anggaran, yaitu fungsi DPRD bersama-sama Pemerintah Daerah untuk menyusun dan menetapkan APBD yang didalamnya termasuk anggaran untuk pelaksanaan fungsi, tugas dan wewenang DPRD; (3) Fungsi Pengawasan, yaitu fungsi DPRD untuk melakukan pengawasan terhadap pelaksanaan undang-undang, peraturan daerah, keputusan kepala daerah serta kebijakan nasional lainnya.

Sebagai daerah otonom, kinerja pegawai pemerintahan Kota Gunungsitoli dibutuhkan aparatur pemerintahan yang berdedikasi tinggi dan memiliki disiplin tinggi serta kinerja pegawai yang berkualitas, seperti Sekretariat DPRD Kota Gunungsitoli yang memiliki tugas pokok dan fungsi menyelenggarakan administrasi kesekretariatan, menyelenggarakan administrasi keuangan serta mendukung pelaksanaan tugas dan fungsi DPRD. Dalam ruang lingkup hubungan kerja sekretariat DPRD Kota Gunungsitoli dalam menjalankan tugas dan fungsinya sangat berat, Namun tidak didukung kemampuan kualitas pegawai yang memadai. Dimana fasilitas pendukung seperti komputer (laptop) belum tersedia berdasarkan tingkat kebutuhan, padahal beban kerja begitu besar. Tuntutan anggota DPRD dalam menjalankan tugas dan fungsinya begitu banyak, tapi tidak didukung kualitas pegawai dan jumlah pegawai yang memadai sesuai dengan tuntutan pekerjaan DPRD Kota Gunungsitoli, seperti halnya tuntutan pada reses, pada saat rapat komisi, rapat paripurna, dan rapat panitia khusus dan rapat badan musyawarah. Berdasarkan hal di atas maka Penulis tertarik untuk membahas tentang Analisis Perencanaan Partisipatif terhadap Pencapaian Kinerja Pegawai pada Kantor Sekretariat DPRD Kota Gunungsitoli

\section{LANDASAN TEORI}

\section{Pengertian Perencanaan}

Pada dasarnya perencanaan dalam suatu instansi sangat dibutuhkan untuk mencapai target yang telah ditentukan. Perencanaan merupakan cara berpikir mengenai persoalan-persoalan sosial dan ekonomi, terutama berorientasi pada masa datang, 
hubungan antara tujuan dan keputusan-keputusan kolektif serta mengusahakan kebijakan dan program.

Tahap awal dalam melakukan aktivitas perusahaan sehubungan dengan pencapaian tujuan organisasi perusahaan adalah dengan membuat perencanaan. Dikemukakan oleh Erly Suandy (2001:2) secara umum perencanaan merupakan proses penentuan tujuan organisasi (perusahaan) dan kemudian menyajikan (mengartikulasikan) dengan jelas strategi-strategi (program), taktik-taktik (tata cara pelaksanaan program) dan operasi (tindakan) yang diperlukan untuk mencapai tujuan perusahaan secara menyeluruh.

Dalam manajemen, perencanaan adalah proses mendefinisikan tujuan organisasi, membuat strategi untuk mencapai tujuan itu, dan mengembangkan rencana aktivitas kerja organisasi. Perencanaan merupakan proses terpenting dari semua fungsi manajemen karena tanpa perencanaan fungsi-fungsi lain pengorganisasian, pengarahan, dan pengontrolan tidak akan dapat berjalan. Rencana dapat berupa rencana informal atau rencana formal. Rencana informal adalah rencana yang tidak tertulis dan bukan merupakan tujuan bersama anggota suatu organisasi. Sedangkan rencana formal adalah rencana tertulis yang harus dilaksanakan suatu organisasi dalam jangka waktu tertentu. Rencana formal merupakan rencana bersama anggota korporasi, artinya, setiap anggota harus mengetahui dan menjalankan rencana itu. Rencana formal dibuat untuk mengurangi ambiguitas dan menciptakan kesepahaman tentang apa yang harus dilakukan.

\section{Fungsi Perencanaan}

Fungsi perencanaan pada dasarnya adalah suatu proses pengambilan keputusan sehubungan dengan hasil yang diinginkan, dengan penggunaan sumber daya dan pembentukan suatu sistem komunikasi yang memungkinkan pelaporan dan pengendalian hasil akhir serta perbandingan hasil-hasil tersebut dengan rencana yang dibuat.

Menurut Sumarto (2003: 55), fungsi dari perencanaan adalah sebagai berikut:

a. Perencanaan sebagai pengarah.

Perencanaan merupakan upaya untuk meraih atau mendapatkan sesuatu secara lebih terkoordinasi. Dalam hal ini perencanaan adalah sebagai 
pengarah atau guide dalam usaha untuk mencapai tujuan secara lebih terkoordinasi dan terarah.

b. Perencanaan sebagai minimalisasi ketidakpastian.

Pada dasarnya di dunia ini tidak ada yang tidak mengalami perubahan. Perubahan-perubahan yang terjadi membawa ketidakpastian bagi organisasi. Kadang perubahan tersebut sesuai dengan apa yang kita inginkan akan tetapi tidak jarang perubahan tersebut tidak sesuai dengan apa yang kita inginkan. Ketidak pastian inilah yang harus diminimalisasikan, dengan adanya perencanaan, ketidak pastian yang akan terjadi di kemudian hari diantisipasi sebelumnya.

c. Perencanaan sebagai minimalisasi pemborosan sumber daya.

Setiap organisasi pasti membutuhkan sumber daya, dengan adanya perencanaan, sebuah organisasi di awal sudah melakukan perencanaan mengenai penggunaan sumber daya sehingga diharapkan tidak terjadi pemborosan dalam hal penggunaan sumber daya yang ada sehingga organisasi tersebut bisa meningkatkan tingkat efisiensinya.

d. Perencanaan sebagai penetapan standar dalam pengawasan kualitas.

Perencanaan berfungsi sebagai penetapan standar dalam pengawasan kualitas yang harus dicapai oleh organisasi dan diawasi pelaksanaannya dalam fungsi pengawasan manajemen.Dalam perencanaan, perusahaan menentukan tujuan dan rencana-rencana untuk mencapai tujuan tersebut.Dalam pengawasan, perusahaan berusaha membandingkan antara tujuan yang telah ditetapkan dengan realita di lapangan, dan mengevaluasi penyimpangan-penyimpangan yang mungkin terjadi, sehingga bisa mengambil tindakan-tindakan yang diperlukan untuk memperbaiki kinerja perusahaan.

\section{Pengertian Kinerja}

Menurut Kusnadi (2003;64), menyatakan bahwa kinerja adalah setiap gerakan, perbuatan, pelaksanaan, kegiatan atau tindakan yang diarahkan untuk mencapai tujuan atau target tertentu. Hariandja (2002;195),mengemukakan kinerja adalah hasil kerja yang dicapai oleh pegawai atau prilaku nyata yang ditampilkan sesuai dengan perannya dalam organisasi. Kinerja pegawai merupakan suatu hal yang sangat penting dalam usaha organisasi mencapai tujuannya, sehingga berbagai kegiatan harus dilakukan 
organisasi tersebut untuk meningkatkannya.

Standar kinerja tersebut ditetapkan berdasarkan kriteria pekerjaan yaitu menjelaskan apa-apa saja yang sudah diberikan organisasi untuk dikerjakan oleh karyawannya, oleh karena itu kinerja individual dalam kriteria pekerjaan haruslah diukur, dibandingkan dengan standar yang ada dan hasilnya harus dikomunikasikan kepada seluruh karyawan.(Mathis dan Jackson, 2002:81), juga menjelaskan "standar kinerja dapat berupa output produksi atau lebih dikenal dengan standar kinerja numerik dan standar kinerja non numeric".

Dari beberapa defenisi diatas, maka penulis dapat menyimpulkan bahwa kinerja adalah suatu hal yang sangat penting dalam melaksanakan tugasnya secara kualitas dan kuantitas yang harus dilakukan oleh seorang pegawai untuk mencapai tujuan atau terget tertentu.

\section{Faktor-faktor yang Mempengaruhi Kinerja}

Menurut Gibson (2003:39), ada tiga perangkat variabel yang mempengaruhi perilaku dan prestasi kerja atau kinerja, yaitu:

1. Variabel Individual, terdiri dari: kemampuan dan keterampilan, mental dan fisik, latar belakang (keluarga, tingkat sosial), penggajian dan demografis (umur, asal-usul, jenis kelamin).

2. Variabel Organisasional, terdiri dari: sumber daya, kepemimpinan, imbalan, struktur desain pekerjaan.

3. Variabel Psikologis, terdiri dari: persepsi, sikap, kepribadian, belajar, motivasi.

Tiga faktor utama yang memengaruhi kinerja individu menurut Mathis dan Robert L (2006:113), adalah "kemampuan individu melakukan pekerjaan tersebut, tingkat usaha yang dicurahkan dan dukungan organisasi”. Dalam konteks pemerintahan sebagai sektor publik menurut Mahsun (2006), bahwa ada beberapa aspek yang dapat dinilai kinerjanya:

1. Kelompok Masukan (input).

2. Kelompok Proses (Proccess).

3. Kelompok Keluaran (Output).

4. Kelompok Hasil (Outcome).

5. Kelompok Manfaat (Benefit). 
6. Kelompok Dampak (Impact).

\section{METODE PENELITIAN}

Lokasi penelitian yang dipilih oleh penulis untuk mendapatkan data-data yang berhubungan dengan penelitian ini yaitu salah satu instansi yakni di Kantor Sekretariat DPRD Kota Gunungsitoli. Jenis penelitian yang dilakukan dalam penelitian ini adalah jenis penelitian kuantitatif. Populasi dalam penelitian ini adalah seluruh pegawai pada Kantor Sekretariat DPRD Kota Gunungsitoli. Teknik pengambilan sampel dalam penelitian ini menggunakan probability sampling. Jika jumlah subjeknya kurang dari 100 lebih baik diambil semua sehingga penelitiannya merupakan penelitian populasi dan jika jumlah subjeknya besar dapat diambil antara $10-15 \%$ atau $20-25 \%$ atau lebih, tergantung dari besar kecilnya resiko yang ditanggung oleh peneliti” Dari pendapat diatas, maka mengingat jumlah populasi tidak terlalu banyak, dalam penelitian ini penulis menetapkan seluruh populasi menjadi sampel sebanyak 24 orang. Sedangkan teknik pengumpulan data dalam penelitian ini adalah dengan menggunakan kuisioner.

\section{TEMUAN-TEMUAN}

\section{Uji Validitas}

Uji validitas adalah suatu alat ukur yang menunjukkan tingkat keandalan atau tingkat kesahitan suatu alat ukur. Jika instrumen dikatakan valid berarti menunjukkan alat ukur yang digunakan untuk mendapatkan data valid sehingga valid berarti instrumen tersebut dapat digunakan untuk mengukur apa yang seharusnya di ukur. Apabila hasil korelasi item dengan total item satu faktor didapat probabilitas $(\mathrm{p})<0,05$ maka dikatakan signifikan dan butir-butir tersebut dianggap valid untuk taraf signifikan sebesar 5\%. Untuk mengetahui tingkat validitas item, maka dilakukan dengan mengkonsultasikan pada tabel harga $\mathrm{r}$ product moment, dengan kepercayaan 95 $\%$.Apabila rhitung $>$ harga kritik dari $\mathrm{r}$ Product Moment, maka item tersebut disebut valid. 
Tabel 4.1

Hasil perhitungan validitas

Nomor 1 sampai dengan 10 variabel $\mathrm{X}$

\begin{tabular}{|c|c|c|c|c|c|c|c|c|}
\hline $\begin{array}{c}\text { Nomor } \\
\text { Item }\end{array}$ & $\sum x$ & $\sum y$ & $\sum x^{2}$ & $\sum y^{2}$ & $\sum x y$ & $r_{h}$ & $r_{t}$ & Ket \\
\hline $\boldsymbol{I}$ & 2 & 3 & 4 & 5 & 6 & 7 & 8 & 9 \\
\hline 1 & 72 & 745 & 224 & 23547 & 2267 & 0,551 & 0.404 & valid \\
\hline 2 & 80 & 745 & 276 & 23547 & 2525 & 0,664 & 0.404 & valid \\
\hline 3 & 77 & 745 & 263 & 23547 & 2455 & 0,790 & 0.404 & valid \\
\hline 4 & 72 & 745 & 222 & 23547 & 2264 & 0,577 & 0.404 & valid \\
\hline 5 & 76 & 745 & 252 & 23547 & 2397 & 0,547 & 0.404 & valid \\
\hline 6 & 75 & 745 & 249 & 23547 & 2382 & 0,686 & 0.404 & valid \\
\hline 7 & 79 & 745 & 275 & 23547 & 2495 & 0,538 & 0.404 & valid \\
\hline 8 & 72 & 745 & 224 & 23547 & 2277 & 0,723 & 0.404 & valid \\
\hline 9 & 66 & 745 & 192 & 23547 & 2084 & 0,530 & 0.404 & valid \\
\hline 10 & 76 & 745 & 250 & 23547 & 2401 & 0,667 & 0.404 & valid \\
\hline
\end{tabular}

Sumber : Kuesioner dan diolah penulis

Dari hasil perhitungan validitas angket diatas diperoleh bahwa item

nomor 1 sampai dengan 10 dinyatakan valid.

Tabel 4.2

Hasil perhitungan validitas

Nomor 11 sampai dengan 20 variabel Y

\begin{tabular}{|c|c|c|c|c|c|c|c|c|}
\hline $\begin{array}{c}\text { Nomor } \\
\text { Item }\end{array}$ & $\Sigma \mathrm{X}$ & $\sum \mathrm{Y}$ & $\Sigma \mathrm{X}^{2}$ & $\Sigma Y^{2}$ & $\sum \mathrm{XY}$ & $r_{h}$ & $r_{t}$ & Ket \\
\hline 1 & 2 & & 4 & 5 & 6 & 7 & 8 & 9 \\
\hline 11 & 76 & 770 & 252 & 25022 & 2470 & 0,527 & 0.404 & valid \\
\hline 12 & 75 & 770 & 247 & 25022 & 2434 & 0,438 & 0.404 & valid \\
\hline 13 & 75 & 770 & 247 & 25022 & 2446 & 0,627 & 0.404 & valid \\
\hline 14 & 78 & 770 & 266 & 25022 & 2550 & 0,573 & 0.404 & valid \\
\hline 15 & 73 & 770 & 235 & 25022 & 2371 & 0,450 & 0.404 & valid \\
\hline 16 & 82 & 770 & 290 & 25022 & 2669 & 0,682 & 0.404 & valid \\
\hline 17 & 77 & 770 & 257 & 25022 & 2494 & 0,419 & 0.404 & valid \\
\hline 18 & 78 & 770 & 262 & 25022 & 2530 & 0,529 & 0.404 & valid \\
\hline 19 & 73 & 770 & 235 & 25022 & 2371 & 0,450 & 0.404 & valid \\
\hline 20 & 83 & 770 & 297 & 25022 & 2687 & 0,428 & 0.404 & valid \\
\hline
\end{tabular}

Sumber: Kuesioner dan diolah penulis

Dari hasil perhitungan validitas angket di atas diperoleh bahwa item nomor 11 sampai dengan 20 dinyatakan valid. 


\section{Uji Reliabilitas}

Tabel 4.3

Perhitungan Koefisien Korelasi Variabel X dan Variabel Y

\begin{tabular}{|c|c|c|c|c|c|}
\hline No. Resp & Skor $(\mathbf{X})$ & Skor $(\mathbf{Y})$ & $\mathbf{X}^{\mathbf{2}}$ & $\mathbf{Y}^{\mathbf{2}}$ & $\mathbf{X Y}$ \\
\hline 1 & 31 & 34 & 961 & 1156 & 1054 \\
\hline 2 & 26 & 29 & 676 & 841 & 154 \\
\hline 3 & 34 & 37 & 1156 & 1369 & 840 \\
\hline 4 & 28 & 30 & 784 & 900 & 1224 \\
\hline 5 & 34 & 36 & 1156 & 961 & 1054 \\
\hline 6 & 31 & 31 & 961 & 1156 & 754 \\
\hline 7 & 31 & 34 & 961 & 841 & 1020 \\
\hline 8 & 26 & 29 & 676 & 900 & 1015 \\
\hline 9 & 34 & 30 & 1156 & 841 & 1295 \\
\hline 10 & 35 & 29 & 1225 & 1369 & 624 \\
\hline 11 & 35 & 37 & 1225 & 676 & 1292 \\
\hline 12 & 24 & 26 & 576 & 729 & 957 \\
\hline 13 & 25 & 27 & 625 & 1156 & 1406 \\
\hline 14 & 38 & 34 & 1444 & 1089 & 1056 \\
\hline 15 & 29 & 33 & 841 & 1369 & 1260 \\
\hline 16 & 38 & 37 & 1444 & 1024 & 725 \\
\hline 17 & 33 & 32 & 1089 & 1296 & 1120 \\
\hline 19 & 35 & 36 & 1225 & 625 & 1225 \\
\hline 20 & 29 & 25 & 841 & 1225 & 1120 \\
\hline 21 & 32 & 35 & 1024 & 1225 & 702 \\
\hline 22 & 35 & 35 & 1225 & 1225 & $\mathbf{2 4 1 5 9}$ \\
\hline 24 & 24 & 35 & 1024 & $\mathbf{2 5 0 2 2}$ & \\
\hline
\end{tabular}

Sumber: Kuisioner dan diolah penulis

$$
\begin{aligned}
& \mathrm{N}=24 \\
& \Sigma \mathrm{X}=745 \\
& \sum \mathrm{Y}=770 \\
& \Sigma X^{2}=23547 \\
& \Sigma Y^{2}=25022 \\
& \Sigma X Y=24159 \\
& \mathrm{r}_{\mathrm{xy}}=\frac{\mathrm{N} \cdot \Sigma \mathrm{XY}-(\Sigma \mathrm{X})(\Sigma \mathrm{Y})}{\sqrt{\left\{\left(\mathrm{N} . . \Sigma \mathrm{X}^{2}-(\Sigma \mathrm{X})^{2}\right\},\left(\mathrm{N} \cdot \Sigma \mathrm{Y}^{2}-(\Sigma \mathrm{Y})^{2}\right\}\right.}} \\
& r_{x y}=\frac{24.24159-(745)(770)}{\sqrt{\left\{24.23547-(745)^{2}\right),\left(24.25022-(770)^{2}\right\}}} \\
& r_{x y}=\frac{579816-573650}{\sqrt{(565128-555025)(600528-592900)}} \\
& \mathrm{r}_{\mathrm{xy}}=\frac{6166}{\sqrt{(10103)(7628)}} \\
& r_{x y}=\frac{6166}{\sqrt{77065684}} \\
& \mathrm{r}_{\mathrm{xy}}=\frac{6166}{8779} \\
& \mathrm{r}_{\mathrm{xy}}=\mathbf{0 . 7 0 2}
\end{aligned}
$$

Dari hasil perhitungan koefisien variabel $\mathrm{X}$ dan Variabel $\mathrm{Y}$ maka diperoleh $\mathrm{r}_{\mathrm{xy}}=$ 0,702 yang dikonsultasikan pada table nilai kritik $\mathrm{r}$ product moment dimana nilai $\mathrm{N}=24$ Pada taraf signifikan $\alpha=5 \%$, dengan nilai $\mathrm{r}_{\text {-tabel }}=0,404$. Dapat disimpulkan bahwa nilai 
$r_{x y}>r_{-t a b e l}$ atau $0,702>0,404$.

Langkah selanjutnya adalah dengan mensubtitusikan nilai $r_{x y}$ tersebut kedalam rumus Spearman Brown berikut:

$$
\begin{aligned}
& r_{i i}=\frac{2 \cdot r^{1} / 21 / 2}{\left(1+r^{1 / 2} 1 / 2\right)} \\
& r_{i i}=\frac{2 \cdot 0,702}{(1+0,702)} \\
& r_{i i}=\frac{1.404}{1,702} \\
& r_{i i}=0,759
\end{aligned}
$$

Dengan $N=24$ pada taraf signifikan $\alpha=5 \%$ diperoleh data $r$-tabel $=0,404$ maka diperoleh $r_{i i}>r_{-}$table atau 0,759>0,404 dinyatakan angket yang disajikan yang berisi item soal variabel $\mathrm{X}$ dan variabel Y sebanyak 20 item adalah RELIABEL.

\section{Uji Hipotesis}

Sebelum melakukan uji hipotesis, maka dilakukan perhitungan kehandalan koefisien korelasi dengan statistik uji t, angka koefisien korelasi di uji dengan menggunakan statistik t dengan perhitungan sebagai berikut:

$$
\begin{aligned}
& t=\frac{\mathrm{r} \sqrt{(\mathrm{n}-2)}}{\sqrt{\left(1-\mathrm{r}^{2}\right)}} \\
& t=\frac{0,702 \sqrt{(24-2)}}{\sqrt{\left(1-(0,702)^{2}\right.}} \\
& t=\frac{0,702 \sqrt{22}}{\sqrt{(1-0.492}} \\
& t=\frac{0,702(4,690)}{\sqrt{0.508}} \\
& t=\frac{3,292}{0.712} \\
& t=\mathbf{4 , 6 2 3}
\end{aligned}
$$

Selanjutnya harga tabel dicari pada tabel distribusi responden pada taraf signifikan $\alpha=0,05$ dan $\mathrm{dk}=24-2$ yakni 22, dimana $t_{\text {hitung }}>\mathrm{t}_{\text {tabel }}$ atau 4,623>2,074, jadi terbukti bahwa hipotesis yang diterima adalah Ha yaitu ada pengaruh perencanaan partisipatif terhadap kinerja pegawai pada Kantor Sekretariat DPRD Kota Gunungsitoli. 


\section{SIMPULAN DAN SARAN}

\subsection{Kesimpulan dan Saran}

Berdasarkan hasil penelitian yang telah dilakukan, maka selanjutnya penulis menyampaikan beberapa kesimpulan-kesimpulan antara lain sebagai berikut.

1. Berdasarkan hasil uji koefisien reliabilitas antara variabel $\mathrm{X}$ dan variabel $\mathrm{Y}$ diperoleh nilai rii sebesar 0,759 maka nilai tersebut dinyatakan reliabel dengan tingkat korelasi yang sangat tinggi.

2. Untuk harga rxy yang didapat tersebut dilakukan uji hipotesis dengan menggunakan statistika $\mathrm{t}$ untuk mengetahui kehandalan korelasi rxy, dan ternyata diperoleh harga $t=4,623>2,074$. Dengan derajat kebebasan Ha diterima dan Ho ditolak.

3. Sehingga dari analisa hasil penelitian penulis menyimpulkan bahwa ada pengaruh perencanaan partisipatif terhadap kinerja pegawai pada Kantor Sekretariat DPRD Kota Gunungsitoli.

Dari hasil penelitian di atas, maka penulis menyarankan beberapa hal yaitu.

1. Disarankan agar perencanaan partisipatif pada Kantor Sekretariat DPRD Kota Gunungsitoli tetap dipertahankan.

2. Disarankan dalam perencanaan partisipatif pada Kantor Sekretariat DPRD Kota Gunungsitoli agar supaya diperinci secara lebih detail.

3. Disarankan bagi pegawai dalam bekerja harus sesuai dengan tugas dan tanggung jawab masing-masing pegawai.

4. Disarankan agar kinerja kerja pegawai pada Kantor Sekretariat DPRD Kota Gunungsitoli dievaluasi secara rutin.

\section{DAFTAR PUSTAKA}

Abe,2002, Perencanaan Daerah Memperkuat Prakarsa Rakyat Dalam Otonomi Daerah.Lapera Pustaka Utama, Yogyakarta.

Arikunto, Suharsimi. 2010. Prosedur Penelitian (Suatu Pendekatan Praktik). Edisi Revisi. Jakarta:PT. Rineka Cipta.

Dharma, Surya. 2001. Manajemen Kinerja. Edisi ketiga. Pustaka Pelajar: Yogyakarta.

Erly, S. 2001. Manajemen Sumber Daya Manusia, Cetakan Ketiga, Jakarta: Kencana Prenada Media Group.

Gibson, et al, 2000, "Organisasi : Perilaku, Struktur, Proses". Edisi kelima, Jilid 1, Cetakan 8, 
Jakarta: Penerbit Erlangga

Handoko, Hani. 2003. Penilaian Kinerja. Ghalia Indonesia. Jakarta.

Hariandja, Marihot T.E, 2002. Manajemen Sumber Daya Manusia. Jakarta: Grasindo.

Ivancevich, John M. 2001. Human Resource Management, Eight Edition, New York: McGraw Hill Companies.

Kusnadi. 2003. Masalah, Kerjasama, Konflik, dan Kinerja. Tanada: Malang.

Mangkunegara, Anwar, Prabu, 2000.Manajemen Sumber Daya Manusia Perusahaan, Bandung: PT Remaja Rosdakarya.

Mathis, dan Jackson, 2002.Manajemen Sumber Daya Manusia, Edisi pertama, Cetakan Pertama, Yogyakarta : Salemba Empat

Mahsun, 2006. Kepemimpinan, Jakarta: Ghalia.

Siagian, Sondang P. 2004. Manajemen Sumber Daya Manusia, Kepemimpinan dan Perilaku Administrasi,Jakarta : Bumi Aksara.

Sugiyono, 2007.Metode Penelitian Kuantitatif, Kualitatif dan R\&D, Bandung: Alfabeta.

Sumarto, Hetifah SJ. 2003. Inovasi, Partisipasi dan Good Governance. Prakarsa Inovatif dan Partisipatif di Indonesia. Jakarta: Yayasan Obor Indonesia.

Waridin.dan Masrukhin, 2006, "Organizational Behavior and Design". Terjemahan Sularno Tjiptowardoyo, Jakarta: Gramedia. 